\title{
A C-band Polymorphism of the X Chromosome in Akodon azarae (Rodentia, Cricetidae)
}

\author{
María Isabel Ortiz¹, G. Dalmasso ${ }^{1}$, R. Dezi², \\ E. Pinna Senn ${ }^{1}$ and J. A. Lisanti ${ }^{1}$ \\ ${ }^{1}$ Departamento de Ciencias Naturales, Facultad de Ciencias, Universidad Nacional de Río Cuarto. (5800) Río Cuarto, Argentina \\ ${ }^{2}$ INEUCI (Instituto de Neurociencia), CONICET (Consejo Nacional de Investigaciones Científicas y Técnicas), Argentina
}

Accepted July 15, 1998

\begin{abstract}
Summary Akodon azarae is one of several rodent species in whose populations XY fully fertile females are found. The chromosomes of 83 specimens ( 40 females, 43 males) from three localities were studied. A high incidence of XY females was observed: 21 of the females presented an XY karyotype. The $\mathrm{X}$ chromosome relative length corresponded to $8.2 \%$ of the genome, but a significative portion of it consisted of C-positive material, giving to the euchromatic part a relative length of $5.07 \%$, in agreement with the estimated size of the eutherian X. Four C-banding patterns (I-IV) of the $\mathrm{X}$ chromosomes were observed, one of them found in only one specimen. The $\mathrm{X}$ chromosome of males was type I, and XY females showed an X of type II or III. XX females presented one X of type I and the other of type I, II, III or (in only one animal) of type IV. The significance of this polymorphism with respect to the XY female phenotype is briefly discussed.
\end{abstract}

Key words Akodon azarae, XY females, X chromosome polymorphism, Sex determination, C-banding polymorphism.

A number of rodent species are characterized by the existence of fully fertile XY females in their populations (revision in Fredga 1988, 1994). In several species of the South American cricetid genus Akodon, fertile females are found that carry an heteromorphic sex pair formed by an $\mathrm{X}$ and a small element that has been considered either as a greatly deleted $\mathrm{X}$ or as an $\mathrm{Y}$ chromosome (Bianchi et al. 1971, 1989, Lobato et al. 1982, Pinna Senn et al. 1993, Vitullo et al. 1986). In Akodon mollis, this small chromosome has been identified cytologically as the Y (Lobato et al. 1982). In the heteromorphic females of $A$. azarae, where this cytological identification is not possible, the presence of the Y specific Zfy and Sry genes has been demonstrated (Bianchi et al. 1989, 1993). Strikingly, the XY females of $A$. azarae manifest an enhanced reproductive performance with respect to XX females (Espinosa and Vitullo 1996). This paper reports the analysis of a Cband polymorphism of the $\mathrm{X}$ chromosome in this species.

\section{Materials and methods}

Cytogenetical studies were performed on 83 specimens of $A$. azarae from three localities in the Southern region of the province of Córdoba: Chucul $\left(32^{\circ} 55^{\prime} \mathrm{S}, 64^{\circ} 10^{\prime} \mathrm{W}\right)$, La Aguada $\left(32^{\circ} 57^{\prime} \mathrm{S}\right.$, $\left.64^{\circ} 39^{\prime} \mathrm{W}\right)$ and Tosquita $\left(33^{\circ} 49^{\prime} \mathrm{S}, 64^{\circ} 28^{\prime} \mathrm{W}\right)$. Standard air-dried preparations from bone marrow were made after injection of $0.20-0.30 \mathrm{ml}$ (according to size) of a $60 \mu \mathrm{g} / \mathrm{ml}$ colchicine solution, $2 \mathrm{hr}$ before sacrifice. C-banding was obtained according to Sumner (1972).

The relative length of the $\mathrm{X}$ chromosome, expressed as percentage of the female genome, was determined in 10 unbanded karyotypes from 6 males from the same locality (Chucul). The relative amount of heterochromatin on the $\mathrm{X}$ was measured on projected photographic negatives of 10 male

Corresponding author: María Isabel Ortiz. 
C-banded metaphases. To search for possible length differences between the different X types (see below), $12 \mathrm{X}$ chromosomes of each type were measured in C-banded cells and their lengths expressed in relation to the length of chromosome 1.

The process of digitalization and posterior analysis of $\mathrm{X}$ chromosomes images was carried out on photographic negatives obtained with a Zeiss Axiophot microscope. The negatives were recorded in digital format by means of a Rex transiluminator (Erlangen), a CCD camera model SVHS Hi 8 (Sony) and an image analyzer VIDAS ver. 2.1 (Kontron Elektronik). The image capture format was $512 \times 512$ pixels, 8 bits per pixel $(\mathrm{b} / \mathrm{w})$. Subsequent operations included: enhancement; segmentation of the $\mathrm{X}$ chromosome in 24 equal, successive segments, perpendicular in each point to the chromosome axis; measuring of the medium optical density (MOD) and calculation of the relative MOD in each segment with respect to each chromosome maximum value; storage and graphic display of the data. For each of the three principal $\mathrm{X}$ types, 10 images were captured. An average graph of each of the C-banding patterns was obtained.

\section{Results and discussion}

We studied 83 specimens of $A$. azarae from three localities in the Southern region of the province of Córdoba: 35 males and 28 females from Chucul, 5 males and 6 females from Tosquita, and 3 males and 6 females from La Aguada. All the specimens showed a 38-chromosomes karyotype fitting previous descriptions (Bianchi and Contreras 1967, Bianchi et al. 1971) and composed of 17 telocentric and a small metacentric autosomal pairs, and the sex pair; the X chromosome is a subterminal element, and the $\mathrm{Y}$ is a small biarmed chromosome. Only the first pair, the small biarmed autosomal pair and the gonosomes can be identified in unbanded cells. The relative length of the X, measured in male cells, corresponded to $8.20 \pm 0.64 \%$ of the genome, a value that is coincident with that reported by Bianchi et al. (1971).

Several females presented an heteromorphic sex pair, considered an XY pair (Bianchi et al. 1989, 1993). Of the 28 females from Chucul, 17 (60.7\%) were heteromorphic (XY). Although the animals here analyzed cannot be considered a representative sample of the population (they were captured during several years), the data do point to a high frequency of XY females in it. Also, 3 of the 6 females from La Aguada and 1 of the 6 from Tosquita showed an XY constitution.

In the study of Bianchi et al. (1971) on animals from Buenos Aires province, 8 of the $25 \mathrm{fe}-$ males analyzed showed this constitution (at the time interpreted as an heterozygocity for a deletion of most of the long arm of the X), and another 5 presented other X chromosome anomalies. The repeated finding of a high proportion of XY females in natural populations of $A$. azarae indicates that no serious effect on fertility or viability is associated with this condition. In fact, it has been shown that, at least in the laboratory, XY females start to reproduce earlier, do it more frequently and stop reproduction later than $\mathrm{XX}$ females, showing similar litter sizes and a lesser preweaning mortality of young (Espinosa and Vitullo 1996).

We analyzed the C-banding pattern in 46 animals from Chucul (28 males, $6 \mathrm{XX}$ and $12 \mathrm{XY}$ females), 11 from Tosquita (5 males, $5 \mathrm{XX}$ and $1 \mathrm{XY}$ females), and 9 from La Aguada ( 3 males, 3 $\mathrm{XX}$ and $3 \mathrm{XY}$ females). Centromeric bands were observed in the autosomes, with the exception of the small metacentric pair, and the $\mathrm{Y}$ chromosome was heterochromatic; the $\mathrm{X}$ chromosome showed several heterochromatic bands of different sizes (Figs. 1-3). The C-heterochromatic bands of the $X$ (measured in male cells) amounted to $38.16 \pm 3.95 \%$ of its length ( $3.13 \%$ of the genome), giving to the euchromatic portion of this chromosome a relative value of 5.07, in agreement with the estimated size of the conserved eutherian X (Ohno 1967).

According to the characteristics and position of the heterochromatic bands, four C-banding patterns could be determined in the X chromosomes of the animals studied (I, II, III, IV, Figs. 1-3). Type IV was found only in one XX specimen from Tosquita. A comparison of the relative lengths 


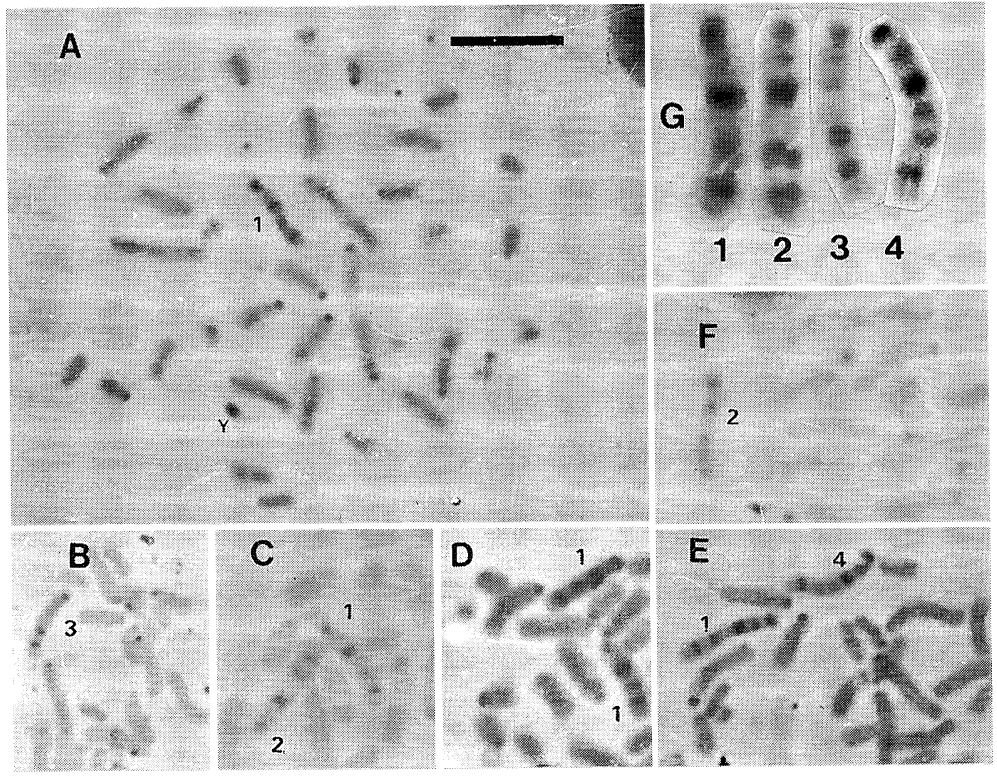

Fig. 1. C-band polymorphism of the $\mathrm{X}$ chromosome in Akodon azarae. A) Male; B and F) XY females (partial photographs); C-E) XX females (partial photographs); G) the four X chromosome types at higher magnification. $\mathrm{X}$ types are indicated by numbers. The bar corresponds to $10 \mu \mathrm{m}$ in $\mathrm{A}-\mathrm{F}$ and to $5 \mu \mathrm{m}$ in $\mathrm{G}$.

of the three principal types, expressed as percent of the length of chromosome 1 , did not reveal significant differences between them (type I, $0.75 \pm 0.05$, type II, $0.76 \pm 0.04$, and type III, $0.76 \pm 0.07 ; \mathrm{F}=0.0093$ ).

As can be seen in Table I, in all the males studied ( 24 from Chucul, 5 from Tosquita and 3 from La Aguada), the X chromosome corresponded to type I. In XX females, one $\mathrm{X}$ was always of type I, which is, obviously, consistent with the paternal origin of one of the $\mathrm{X}$ chromosomes in these females; the other was of type I, II or III, with the previously indicated exception of an animal from Tosquita, where it was of type IV. All XY females, on the other hand, showed an X chromosome of type II or III.

A digital image analysis was performed on a sample of 10 chromosomes of each of the types I, II and III. The method employed allowed an objective comparison of the different densitometric patterns observed (Fig. 3).

C-band polymorphism is a frequent cytogenetical observation, usually without phenotypic expression. The polymorphism of the X-chromosome here described does not seem to conform to this rule, but no simple explanation of the data is evident. At first glance, it could be thought that only type I X chromosome is compatible with male differentiation, the other types probably carrying a mutation responsible for the sex reversal, resembling the situation found in the XY females of Myopus schisticolor (Fredga et al. 1976, Herbst et al. 1978). However, A. azarae XY females are born 


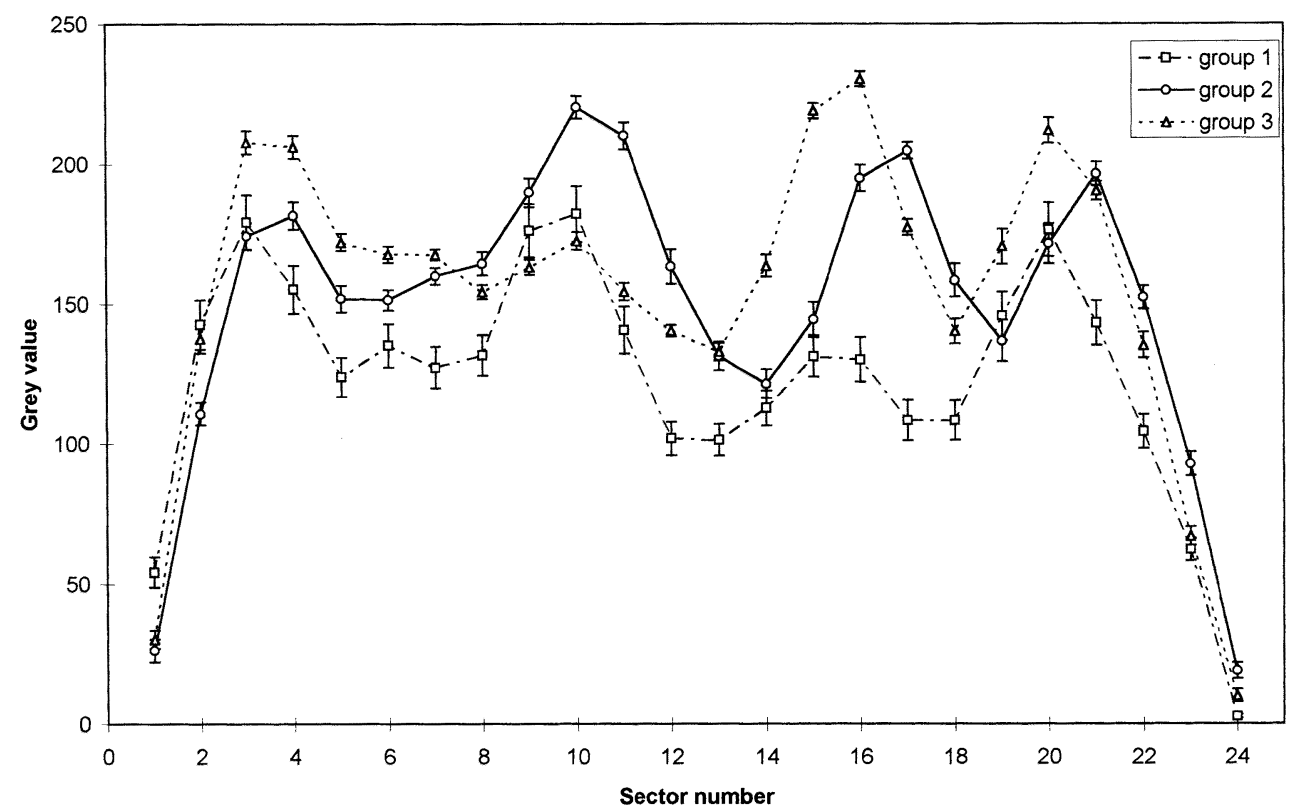

Fig. 3. Graphic representation of Akodon azarae X chromosome types I, II and III on the basis of medium grey values in each chromosome segment.

Table 1. Number of Akodon azarae specimens of different chromosome constitutions with respect to X chromosome types

\begin{tabular}{|c|c|c|c|c|c|c|c|}
\hline \multirow{2}{*}{ Locality } & \multirow{2}{*}{$\frac{\text { Males }}{\mathrm{X}_{1} \mathrm{Y}}$} & \multicolumn{6}{|c|}{ Females } \\
\hline & & $\mathrm{X}_{2} \mathrm{Y}$ & $\mathrm{X}_{3} \mathrm{Y}$ & $\mathrm{X}_{1} \mathrm{X}_{1}$ & $\mathrm{X}_{1} \mathrm{X}_{2}$ & $X_{1} X_{3}$ & $\mathrm{X}_{1} \mathrm{X}_{4}$ \\
\hline Chucul & 28 & 6 & 6 & 1 & 2 & 3 & - \\
\hline Tosquita & 5 & 1 & - & 1 & 2 & 1 & 1 \\
\hline La Aguada & 3 & - & 3 & - & 1 & 2 & - \\
\hline
\end{tabular}

only from other XY females (Lizarralde et al. 1982); they should also be produced by normal XX female $\times$ male crosses if an $\mathrm{X}$-linked mutation were responsible per se for the sex reversal. Given this mode of inheritance, a mutation on the $\mathrm{Y}$ chromosome was postulated as the cause of the $\mathrm{XY}$ female phenotype in A. azarae (Bianchi et al. 1993). However, no difference between males and $\mathrm{XY}$ females was detected in the nucleotide sequence of a partial open reading frame of the conserved region of Sry (Bianchi et al. 1993). An analysis of the hereditary transmission of the different $\mathrm{X}$ types is under way.

\section{Acknowledgements}

We wish to thank Dr. Jaime Polop for providing the animals here studied. This work was supported by a grant from the Secretaría de Ciencia y Técnica, UNRC.

\section{References}

Bianchi, N. O. and Contreras, J. R. 1967. The chromosomes of the field mouse Akodon azarae (Cricetidae, Rodentia) with special reference to sex chromosome anomalies. Cytogenetics 6: 306-313. 
-, Reig, O. A., Molina, O. J. and Dulout, F. N. 1971. Cytogenetics of the South American Akodont rodents (Cricetidae). I. A progress report of Argentinian and Venezuelan forms. Evolution 25: 724-736.

-, De la Chapelle, A., Vidal-Rioja, L. and Merani, S. 1989. The sex-determining zinc finger sequences in XY females of Akodon azarae (Rodentia, Cricetidae). Cytogenet. Cell Genet. 52: 162-166.

-, Bianchi, M. S., Bailliet, G. and De la Chapelle, A. 1993. Characterization and sequencing of the sex determining region Y gene (Sry) in Akodon (Cricetidae) species with sex reversed females. Chromosoma 102: 389-395.

Espinosa, M. B. and Vitullo, A. D. 1996. Offspring sex-ratio and reproductive performance in heterogametic females of the South American field mouse Akodon azarae. Reproduction in heterogametic Akodon azarae females. Hereditas 124: $57-62$.

Fredga, K. 1988. Aberrant chromosomal sex-determining mechanisms in mammals, with special reference to species with XY females. Phil. Trans. Royal Soc. London, Ser. B 322: 83-95.

- 1994. Bizarre mammalian sex-determining mechanisms. In: Short, R. V. and Balaban, E. (eds.) The Differences between the Sexes. Cambridge University Press.

-, Gropp, A., Winking, H. and Frank, F. 1976. Fertile XX- and XY-type females in the wood lemming Myopus schisticolor. Nature 261: 225-227.

Herbst, E. W., Fredga, K., Frank, F., Winking, H. and Gropp, A. 1978. Cytological identification of two X-chromosome types in the wood lemming (Myopus schisticolor). Chromosoma 69: 185-191.

Lizarralde, M. S., Bianchi, N. O. and Merani, M. S. 1982. Cytogenetics of South American Akodont rodents (Cricetidae). VII. Origin of sex chromosome polymorphism in Akodon azarae. Cytologia 47: 183-193.

Lobato, L., Cantos, G., Araujo, B., Bianchi, N. O. and Merani, S. 1982. Cytogenetics of South American Akodont rodents (Cricetidae). X. Akodon mollis: a species with XY females and B chromosomes. Genetica 57: 199-205.

Ohno, S. 1967. Sex Chromosomes and Sex Linked Genes. Springer Verlag.

Pinna Senn, E., Barale, G. D. de, Polop, J., Ortiz, M. I., Provensal, M. C. and Lisanti, J. A. 1993. Estudio cariotípico y morfométrico en una población de Akodon sp. (Rodentia, Cricetidae) de Pampa de Achala. Mendeliana 10: 59-70.

Sumner, A. T. 1972. A simple technique for demonstrating centromeric heterochromatin. Exp. Cell Res. 75: 304-306.

Vitullo, A., Merani, M., Reig, O., Kajon, A., Scaglia, O., Espinosa, M. and Pérez-Zapata, A. 1986. Cytogenetics of South American Akodont rodents (Cricetidae): new karyotypes and chromosomal banding patterns of Argentinian and Uruguayan forms. J. Mammal. 67: 69-80. 